\title{
Molecular differentiation of four Reptalus species (Hemiptera: Cixiidae)
}

\author{
S. Bertin ${ }^{1} \dagger$, L. Picciau ${ }^{1} \dagger$, Z. Ács ${ }^{2}$, A. Alma ${ }^{1}$ and D. Bosco ${ }^{1 *}$ \\ ${ }^{1}$ DIVAPRA - Entomologia e Zoologia applicate all'Ambiente \\ 'Carlo Vidano', Università di Torino, Via L. da Vinci 44, \\ 10095 Grugliasco (TO), Italy: ${ }^{2}$ Fitolab Plant Pest Diagnostic and \\ Advisory Ltd. Istenhegyi út 29, Budapest H-1125, Hungary
}

\begin{abstract}
The cixiid species Reptalus quinquecostatus, R. cuspidatus, R. panzeri and $R$. melanochaetus are widely distributed in Europe and are receiving growing attention because of their potential role as phytoplasma vectors. Identifying the Reptalus species is restricted to a few specialist entomologists and relies on the morphology of the male genitalia, hampering the identification of juveniles and females. This study provides the tools for species discrimination by integrating the morphological description, which is primarily for the genus identification, with new molecular assays, based on both ribosomal and mitochondrial DNA. PCRRFLP assays carried out on the mitochondrial cytochrome oxidase I gene (COI) with $A l u \mathrm{I}$ provided species-specific profiles for the four Reptalus species. Amplification of a ribosomal internal transcribed spacer (ITS2) region produced species-specific fragments of different sizes for $R$. quinquecostatus, $R$. melanochaetus, $R$. cuspidatus and R. panzeri. The digestion of the ITS2 PCR product with TaqI allowed the discrimination of these latter two species. This molecular identification key ensures reliable results and can be successfully applied not only to adults, but also to the nymphs feeding on the roots. The identification of the nymphs (i) extends the collection period of these monovoltine species to the whole year (adults are present for a short summer period) and (ii) allows the unambiguous identification of their actual host plants because nymphs are steady on the root system while adults tend to disperse onto other plants. Fast and reliable identification of the Reptalus species provides useful help in monitoring activities and, therefore, in designing rational control strategies to protect crops from phytoplasma infection.
\end{abstract}

Keywords: Cixiidae, species identification, ITS2, mtCOI, PCR-RFLP, DNA barcoding

(Accepted 8 October 2009)

\section{Introduction}

The genus Reptalus (Hemiptera: Cixiidae) includes 11 recognised species distributed in the temperate areas of central

*Author for correspondence

Fax: 390116708535

E-mail: domenico.bosco@unito.it

$\dagger$ The first two authors contributed equally to the paper. and southern Europe and the Mediterranean basin (Hoch, 2004 available online at 'http://www.faunaeur.org').

Though phylogenetic relationships between Reptalus and the other cixiid genera have been recently clarified (Ceotto \& Bourgoin, 2008; Ceotto et al., 2008), the biology and behaviour of the Reptalus species remain poorly known because of the peculiar characteristics of this planthopper family. The lifecycle of cixiids is closely related to their host plants, which are exploited for feeding, mating and oviposition and serve as protection against predators (Wilson et al., 
Table 1. Field-collected samples and their host plants.

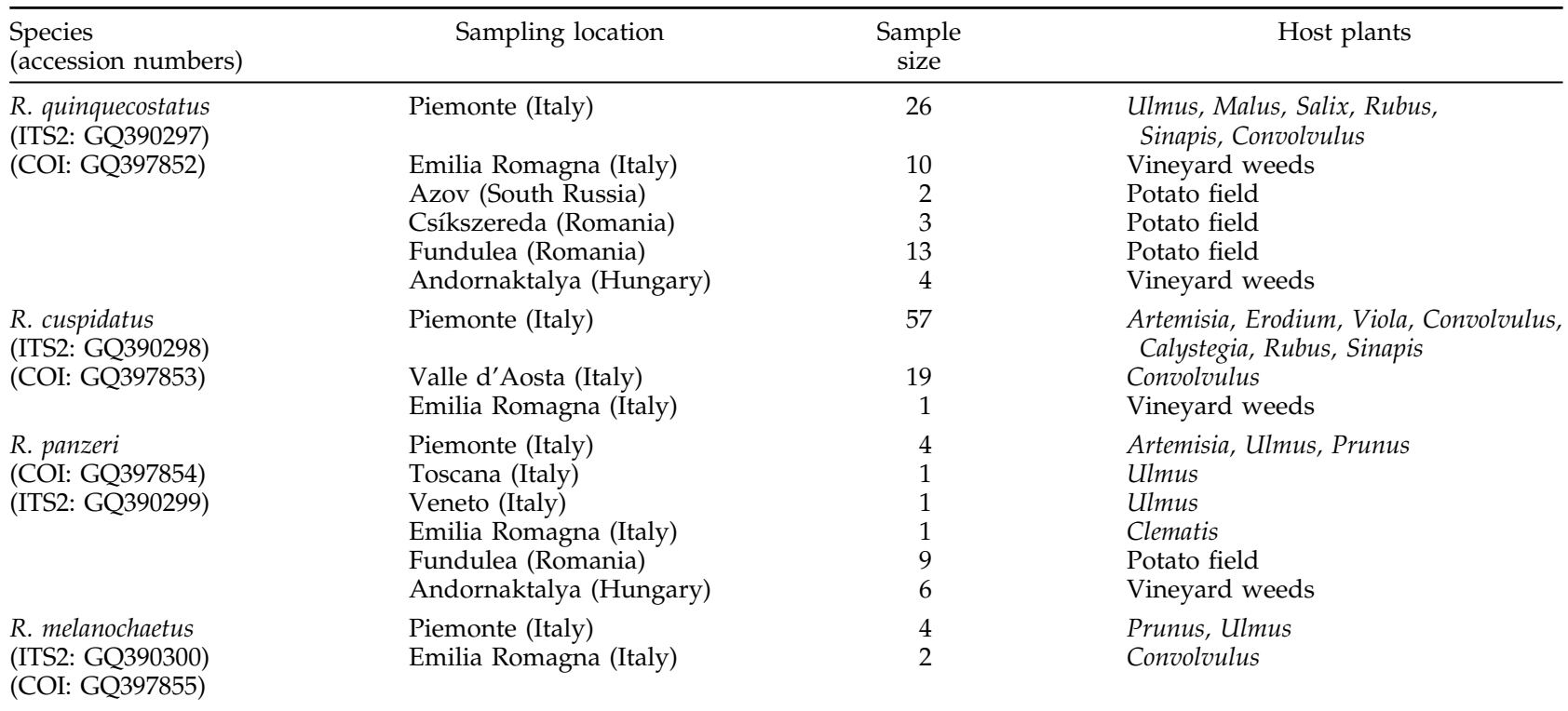

1994; Sforza \& Bourgoin, 1998). Adult females lay eggs in the soil near the base of a host plant, and the five nymphal instars live underground and feed on its roots. Newly emerged adults fly to leaves and shoots for feeding and mating (Wilson \& Tsai, 1982; O’Brien \& Wilson, 1985). A broad host-plant range has been identified, and the available data indicate that different cixiid species belonging to the same genus may feed on distantly related plant families (Wilson et al., 1994). The cixiids are mostly phloemfeeders, and their sap-sucking habit makes them potential vectors of phloem-inhabiting plant pathogens. Indeed, several species are known as vectors of viruses, bacteriumlike organisms and phytoplasmas (Julia et al., 1985; Danet et al., 2003; Weintraub \& Beanland, 2006). In Europe, several crops (beet, maize, strawberry, solanaceous and grapevine) are affected by different diseases vectored by cixiids (Sforza et al., 1998; Danet et al., 2003; Březíková \& Linhartová, 2007; Jović et al., 2007; Bressan et al., 2008).

Within the genus Reptalus, some species have recently been noted as potential vectors of phytoplasmas belonging to the stolbur group (Candidatus Phytoplasma solani, 16SrXII-A genetic group). Individuals of Reptalus panzeri (Löw) collected in maize fields affected by maize redness, a disease recently associated to a phytoplasma infection (Duduk \& Bertaccini, 2006), tested positive for stolbur in PCR assays. In further studies, the efficiency of this species to transmit stolbur to healthy maize plants was confirmed by transmission trials in mesh cages (Jović et al., 2007). Some Reptalus species are also suspected to be vectors of a serious grapevine yellow, known as bois noir (BN). BN is an endemic stolbur disease of grape-growing areas in Europe, Asia Minor and the Mediterranean basin and has shown an increasing economic importance over the past years (Maixner, 2006). Although the only confirmed vector of $\mathrm{BN}$ is the cixiid Hyalesthes obsoletus (Signoret), R. panzeri and Reptalus quinquecostatus (Dufour) collected in affected vineyards have been found positive to stolbur phytoplasma (Palermo et al., 2004; Trivellone et al., 2005; Riedle-Bauer et al., 2006). It has also been demonstrated that $R$. quinquecostatus can successfully inoculate $\mathrm{BN}$ into an artificial feeding medium through parafilm (Pinzauti et al., 2008). The potential involvement of Reptalus in phytoplasma transmission has prompted an active monitoring practice. The epidemiological studies and application of control strategies rely on careful surveys of the spread of cixiid species. The reliable identification of each species becomes essential, but may sometimes produce uncertain results. Identification of cixiids, including Reptalus, is based on morphological characteristics and restricted to a small number of specialist entomologists with broad experience of this insect family. Even for experts, the morphological distinction of closely related species remains difficult. Furthermore, the main taxonomic characteristics concern the male genitalia, thus hampering the identification of juveniles and adult females.

DNA-based approaches offer valuable support to traditional taxonomic methods and nowadays are widely employed for insect species identification. Considering both chromosomal and extra-chromosomal DNA, the ribosomal and mitochondrial regions have proven informative for taxonomic purposes. Notably, the internal transcribed spacer regions (ITS1 and 2) of the ribosomal operons are highly polymorphic and support phylogenetic analyses at species level (Li, 2007; Roe \& Sperling, 2007). Among the mitochondrial sequences, the cytochrome oxidase I gene (COI) is frequently employed (Behere et al., 2008; Sinclair \& Gresens, 2008) and has been chosen as the reference point for DNA barcoding, a universal system of animal species identification. DNA barcoding is based on the premise that sequence diversity within a short, standardised segment of the genome (on average $600-800 \mathrm{bp}$ ) can provide a 'biological barcode' that enables identification to the species level (Hebert et al., 2003; Hebert \& Gregory, 2005). Previous studies have shown that the COI polymorphism can effectively resolve species recognition (Hebert et al., 2004; Hogg \& Hebert, 2004; Smith et al., 2005). 
a

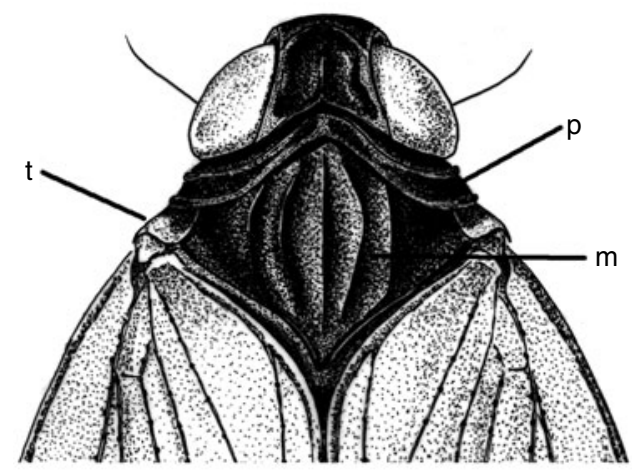

b

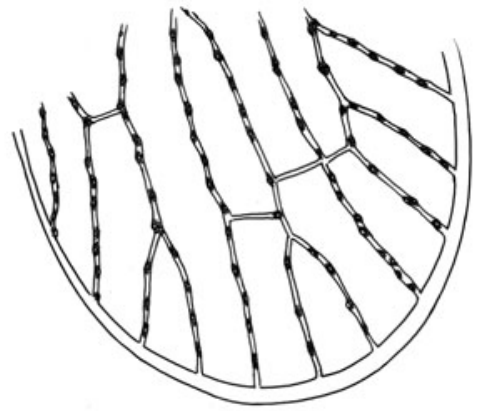

C

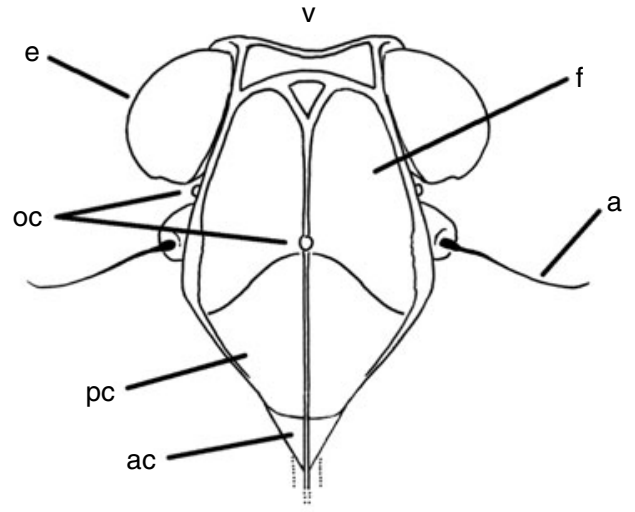

d

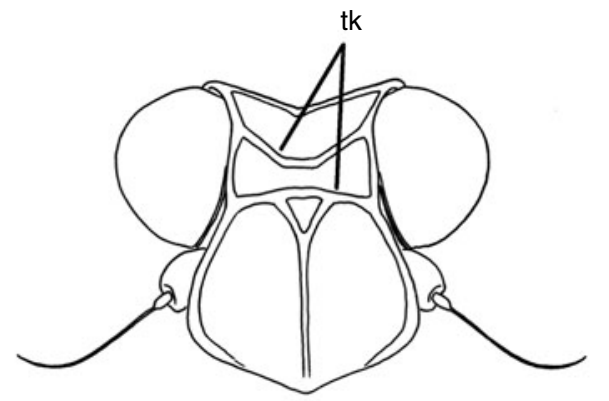

e

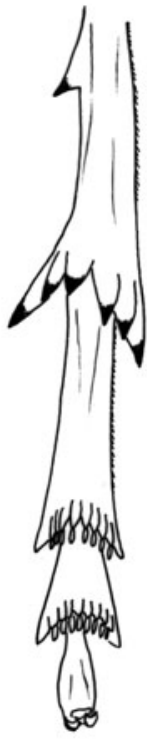

Fig. 1. External morphological features of Reptalus genus: (a) head and thorax; $t$, tegula; $p$, pronotum; $m$, mesothorax with five evident carinae; (b) tip of a forewing showing the veins with tubercles; (c) head of $R$. quinquecostatus in frontal view; a, antenna; ac, anteclypeus; e, eye; f, front; oc, ocelli; pc, postclypeus; v, vertex; (d) detail of vertex; tk, transverse keels; (e) hind tarsus of R. cuspidatus (subgenus Trepalus) showing the first segment with spines bearing platellae.

The aim of this study was to provide a molecular identification key of the most common European Reptalus species (Holzinger et al., 2003; Hoch, 2004). We tested the reliability of both ITS2 and COI DNA polymorphisms for the identification of four species, $R$. quinquecostatus (subgenus Reptalus), Reptalus cuspidatus (Fieber) (subgenus Trepalus), $R$. panzeri (subgenus Reptalus) and Reptalus melanochaetus (Fieber) (subgenus Reptalus) and correlated morphological characteristics of the different species with species-specific DNA profiles.

\section{Material and methods \\ Samples collection}

Adults of R. quinquecostatus $(n=58), R$. cuspidatus $(n=77)$, $R$. panzeri $(n=22)$ and $R$. melanochaetus $(n=6)$ were fieldcollected from different Italian and eastern European regions during the summers of 2007 and 2008. Field surveys were mainly targeted at those plants known as potential hosts of the Reptalus species (Holzinger et al., 2003; Mazzoni, 2005) and those potentially infected by stolbur phytoplasma (table 1).

Specimens of both sexes were preserved in absolute ethanol until their morphological identification and/or DNA extraction.

\section{Morphological species identification}

Specimens were individually identified with a stereo microscope and the external morphological features were used to determine family and genus. For species identification, male genitalia (aedeagus, parameres and anal tube) were carefully dissected and placed in a $10 \%$ potassium

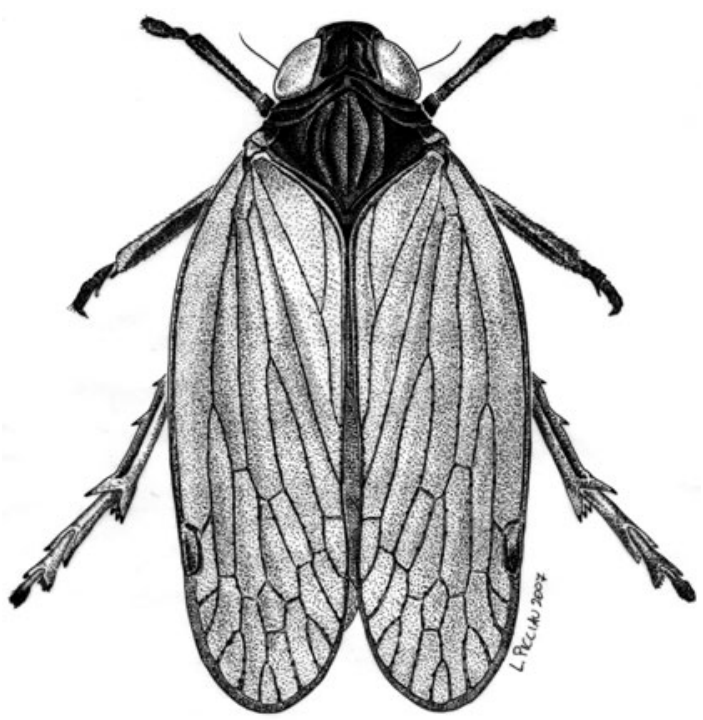

Fig. 2. Reptalus quinquecostatus: habitus in dorsal view. Scale bar: $1 \mathrm{~mm}$. 
a
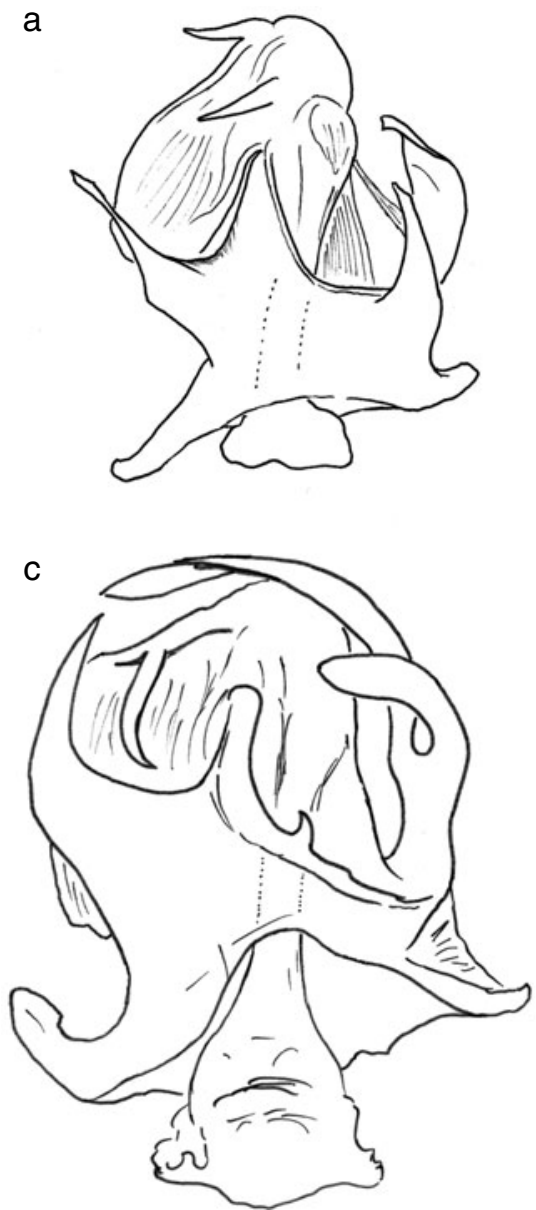

b

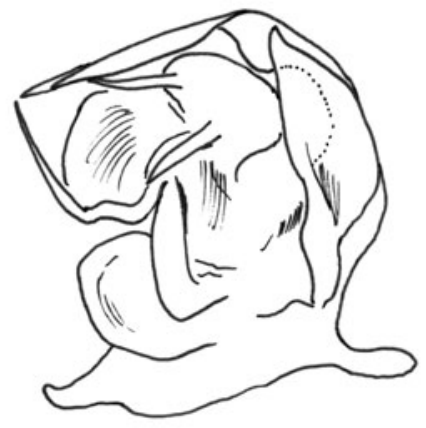

d

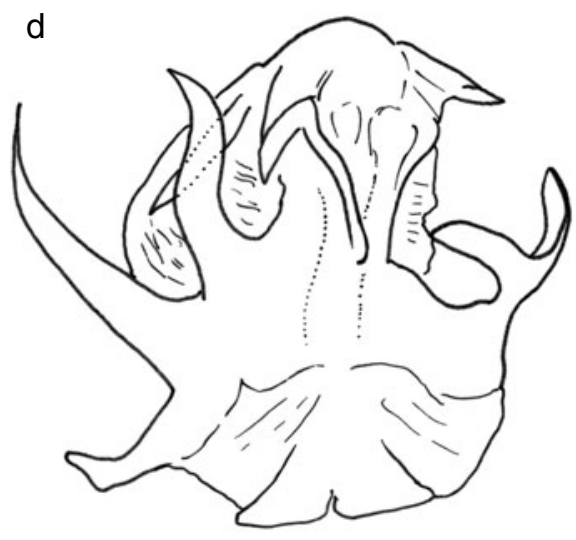

The amplification of the ITS2 region was carried out with the primers ITS2 $\mathrm{fw}$ (5'-TGTGAACTGCAGGACACATG-3') and ITS2rv (5'-ATGCTTAAATTTAGGGGGTA-3'), which respectively anneal on 5.8S and $28 \mathrm{~S}$ ribosomal regions (Collins \& Paskewitz, 1996). PCR was performed in $25 \mu \mathrm{l}$ reaction volume containing: $1 \times \mathrm{PCR}$ buffer $(20 \mathrm{mM}$ Tris- $\mathrm{HCl}$ $\mathrm{pH} 8.4,50 \mathrm{mM} \mathrm{KCl}), 1.5 \mathrm{mM} \mathrm{MgCl} 2,200 \mu \mathrm{M}$ of each dNTP, $0.5 \mu \mathrm{M}$ of each primer, 1 unit of Taq polymerase (Invitrogen, Carlsbad, CA) and 50-150 ng of template DNA. The thermocycling conditions consisted of an initial denaturation cycle at $94^{\circ} \mathrm{C}$ for $5 \mathrm{~min}, 35$ cycles at $94^{\circ} \mathrm{C}$ for $30 \mathrm{~s}, 58^{\circ} \mathrm{C}$ for $45 \mathrm{~s}$ and $72^{\circ} \mathrm{C}$ for $1 \mathrm{~min}$ and a final cycle at $72^{\circ} \mathrm{C}$ for $10 \mathrm{~min}$.

A fragment of COI mitochondrial gene was amplified using the primers C1-J-2195 (5'-TTGATTTTTTGGTCATCCAGAAGT-3') and TL2-N-3014 (5'-TCCAATGCACTAATCTGCCATATTA-3') (Simon et al., 1994). The PCR conditions were the same as described for ITS2 amplification, except the $\mathrm{MgCl}_{2}$ content (increased to $2.5 \mathrm{mM}$ ) and the annealing step $\left(54^{\circ} \mathrm{C}\right.$ for $\left.1 \mathrm{~min}\right)$.

Products of both PCR assays were separated by electrophoresis onto a $1 \%(\mathrm{w} / \mathrm{v})$ agarose gel and then directly purified from the amplification tube using the PureLink ${ }^{\mathrm{TM}}$ 

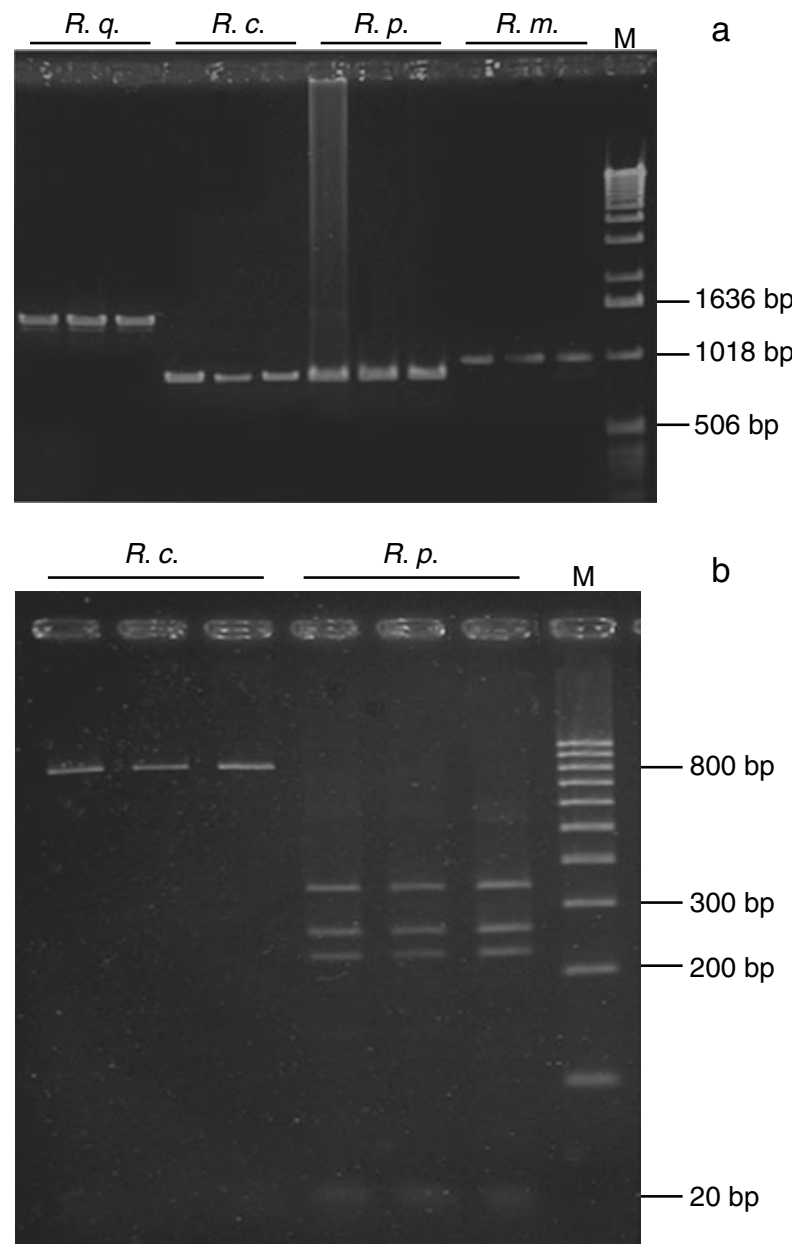

Fig. 4. (a) agarose gel electrophoresis of ITS2 PCR products from the four Reptalus species. R.q., R. quinquecostatus; R.c., R. cuspidatus; R.p., R. panzeri; R.m., R. melanochaetus; M: molecular weight marker (1 kb ladder); (b) RFLP profile after TaqI digestion of the ITS2-PCR product for the two species $R$. cuspidatus and R. panzeri. R.c.: R. cuspidatus; R.p.: R. panzeri; M: molecular weight marker (100 bp ladder).

PCR Purification Kit (Invitrogen, Carlsbad, CA, USA). The ITS2 and COI purified products were sequenced (Bio-Fab Research, Pomezia, Italy) in both directions using the respective forward and reverse primers. The mitochondrial and ribosomal consensus sequences of each Reptalus species have been deposited in GenBank (National Centre for Biotechnology Information, NCBI). Accession numbers for ITS2 sequences: GQ390297-GQ390300; accession numbers for COI sequences: GQ397852-GQ397855 (table 1). COI sequences are also available in Barcode of Life databank.

\section{RFLP analysis}

Restriction sites on both ITS2 and COI sequences were predicted using Webcutter 2.0 (available online at 'http:// rna.lundberg.gu.se/cutter2/'). The ITS2 fragments amplified from the $R$. cuspidatus and $R$. panzeri species were digested with the TaqI restriction enzyme at $65^{\circ} \mathrm{C}$ for $2 \mathrm{~h}$. COI amplicons from all tested species were subjected to AluI restriction activity at $37^{\circ} \mathrm{C}$ for $2 \mathrm{~h}$.

For both ITS2 and COI samples, $5 \mu \mathrm{l}$ of PCR product was digested with one unit of the proper enzyme in a $15 \mu \mathrm{l}$ reaction volume, according to the manufacturer's instructions (Invitrogen, Carlsbad, CA, USA). The restriction fragments were separated by electrophoresis on $2 \%(\mathrm{w} / \mathrm{v})$ $1 \times$ TBE agarose gels (MetaPhore agarose for resolution of small nucleic acids; Cambrex, Rockland, ME, USA) at $70 \mathrm{~V}$ for $2 \mathrm{~h}$ and stained with ethidium bromide.

\section{Results}

\section{Morphological species identification}

A brief review of the external characteristics for identifying cixiids among the different Auchenorrhyncha taxa is given. The main features of the infraorder Fulgoromorpha are (i) the presence of a tegula at the base of each forewing (fig. 1a) and (ii) two typically 'Y-shaped' anal veins on the clavus. A short anteclypeus and the median coxae clearly separated at the base are also present.

The family Cixiidae is quite easily distinguishable from the other Fulgoromorpha by the large and transparent forewings, surpassing the tip of the abdomen, with distinct venations, often with tubercles (fig. 1b). These forewings are held roof-like in the rest position and sometimes overlap slightly apically. The frons is wide, with three keels giving a distinctive aspect to the species belonging to this family. Three ocelli are normally present, two laterally and one in the middle on the frons (fig. 1c). The pronotum is short and collar-like. The mesonotum is quite large, subtriangular and bears three or five longitudinal carinae (fig. 1a). The hind tibiae have a row of apical spines and no movable spurs. The genus Reptalus differs from the other genera principally by bearing five distinct longitudinal carinae on the mesonotum (fig. 1a), and two transverse keels on the head (fig. 1d). The size of the body normally exceeds $5 \mathrm{~mm}$ in length. The first segment of the hind tarsus bears apical spines with platellae (macrochaetae) in the subgenus Trepalus (fig. 1e); platellae are absent in the subgenus Reptalus. Finally, the head in lateral view appears obtuse (Ossiannilsson, 1978; Holzinger et al., 2003; Wilson, 2005). An overview of the insect body is given for $R$. quinquecostatus (fig. 2).

The Reptalus species identification mainly relies on the shape of the aedeagus. The drawings representing the aedeagi of the four considered species are provided in fig. 3 in order to show the distinctive features. Parameters and anal tube are omitted.

\section{ITS2 sequence: PCR and RFLP analyses}

The ITS2 region was successfully amplified from each of the four Reptalus species, providing fragments with the following sizes: $1450 \mathrm{bp}$ for $R$. quinquecostatus; $850 \mathrm{bp}$ for $R$. cuspidatus and R. panzeri; and $960 \mathrm{bp}$ for $R$. melanochaetus (fig. 4a). The four species shared a similar sequence within the first $200 \mathrm{bp}$ and the last $550 \mathrm{bp}$ of the ITS2 region (range of similarity scores: $89-93 \%$ ); a diverse number of repeats occurred between these two ends, leading to different fragment lengths. 

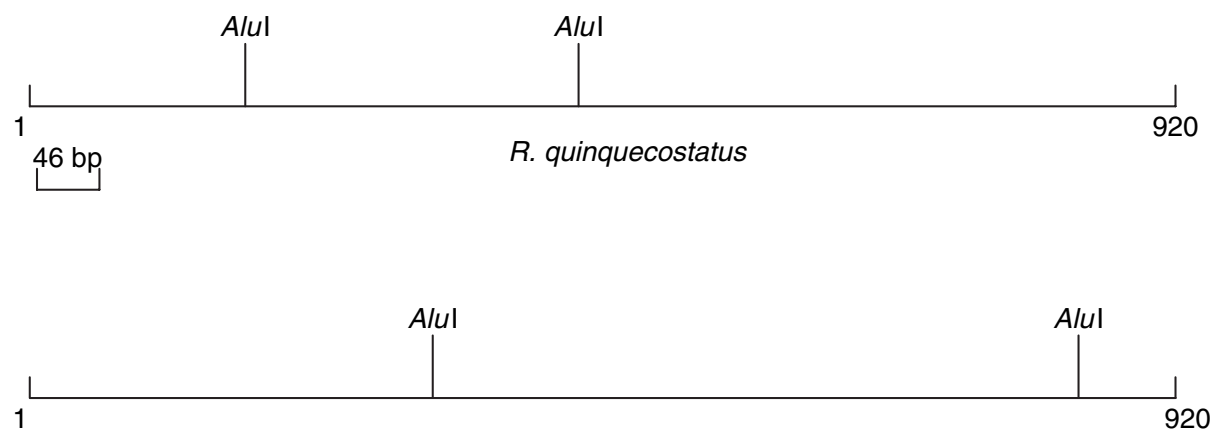

R. cuspidatus

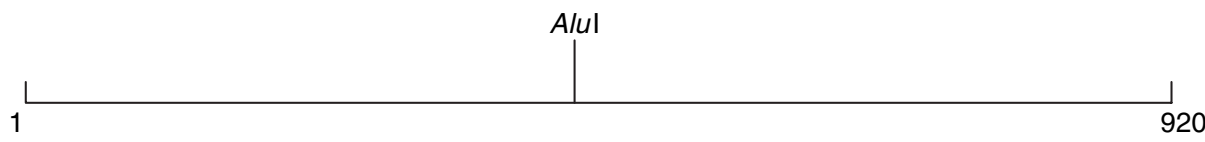

R. panzeri

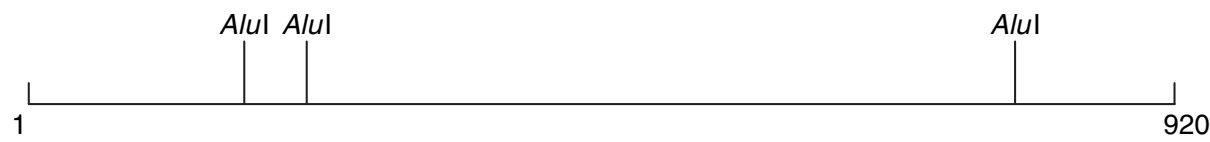

R. melanochaetus

Fig. 5. AluI restriction sites of the four Reptalus species.

The sequence analysis revealed no polymorphism among the individuals belonging to the same species and, consequently, no differences amenable to the geographical origin, host plant or sex were noticed. The absence of polymorphism at the intra-specific level led us to exclude any variability among the different ribosomal units within the same individual genome.

The ITS2 amplicon length polymorphism did not enable us to distinguish between the $R$. cuspidatus and R. panzeri species. In this case, the correct species identification was achieved by further performing a RFLP assay. The TaqI digestion produced four restriction fragments for $R$. panzeri ( $\sim 20 \mathrm{bp}, \sim 230 \mathrm{bp}, \sim 260 \mathrm{bp}, \sim 340 \mathrm{bp}$ ), while no TaqI restriction sites were present within the $R$. cuspidatus sequence (fig. $4 b)$.

\section{COI sequence: PCR and RFLP analyses}

Amplification of the mitochondrial COI gene from all tested individuals always provided a $920 \mathrm{bp}$ fragment. The alignment of the COI sequences revealed a certain degree of polymorphism among the four different species, while no variability was recorded within the same species. Polymorphisms were found at the $A l u \mathrm{I}$ recognition site (AGCT), generating species-specific digestion patterns (fig. 5). According to the mutation points revealed by sequencing, the endonuclease activity produced three restriction fragments for R. quinquecostatus ( $\sim 170 \mathrm{bp}, \sim 260 \mathrm{bp}, \sim 490 \mathrm{bp})$ and $R$. cuspidatus $(\sim 80 \mathrm{bp}, \sim 330 \mathrm{bp}, \sim 510 \mathrm{bp})$, two restriction fragments for $R$. panzeri $(\sim 440 \mathrm{bp}, \sim 480 \mathrm{bp})$ and four restriction fragments for $R$. melanochaetus $(\sim 60 \mathrm{bp}, \sim 120 \mathrm{bp}$, $\sim 170 \mathrm{bp}, \sim 570 \mathrm{bp}$ ) (fig. 6). The smallest fragments (60 bp for $R$. melanochaetus and $80 \mathrm{bp}$ for $R$. cuspidatus), even though faint, could be detected by agarose gel electrophoresis. The RFLP patterns were constant within each species, confirming the absence of variability at an intra-specific level.

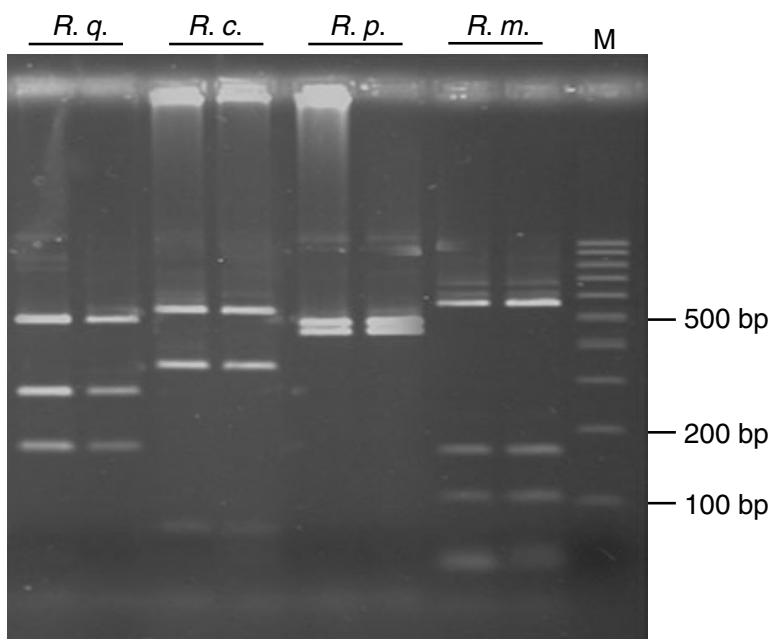

Fig. 6. RFLP profile after AluI digestion of the COI-PCR product for the four Reptalus species. R.q., R. quinquecostatus; R.c., R. cuspidatus; R.p., R. panzeri; R.m., R. melanochaetus; M: molecular weight marker (100 bp ladder). 


\section{Discussion}

This study provides a comprehensive description of both morphological and molecular tools for species discrimination within the genus Reptalus. R. cuspidatus and $R$. panzeri were abundant in Italy and eastern Europe, respectively, while $R$. quinquecostatus was widespread in all the considered areas. $R$. melanochaetus was shown to be less represented in the investigated areas, according to Mazzoni (2005), who did not report this species in his recent surveys of Auchenorrhyncha in Tuscany, Central Italy.

Two different DNA regions, ribosomal ITS2 and mitochondrial COI, allowed discrimination at the species level. Both sequences diverged among the four Reptalus species and were suitable for correctly assigning the individuals to each species in accordance with the previous morphological identification. The absence of within-species polymorphisms proves the species-specificity of both ITS2 and COI markers.

The ITS2 PCR allowed us to recognise two of the four Reptalus species directly by amplicon size polymorphism. A further RFLP analysis was required when an $850 \mathrm{bp}$ fragment, corresponding to both the R. cuspidatus and $R$. panzeri species, was amplified. Despite their length polymorphism, ITS2 sequences possess similar regions in all of the four species. It is possible that such conserved domains were part of a precursor rRNA and have been differently truncated or extended during rDNA duplication. This could have produced diverse sequences or alleles then become fixed separately during speciation (Koekemoer et al., 2009).

Hence, the ITS2 region provided the simplest tool for rapid Reptalus identification because the PCR assay was sufficient for recognising at least two species. Unambiguous species discrimination also can be achieved by routinely performing RFLP assays on COI-PCR products. In this case, the sole $A l u \mathrm{I}$ enzyme allowed clear differentiation of the four species with a unique restriction reaction.

The reliability of the ITS2 and COI markers has been tested on different populations from different sites in Italy and eastern Europe and no polymorphisms ascribable to the geographic origins have been noticed. The two regions also showed stable PCR or RFLP patterns irrespective of the different plants hosting the insects. Given their conservation and specificity, both ribosomal and mitochondrial regions can be considered potential identification keys. These new tools require rapid and handy procedures and may contribute to broadening the current handful of competent scientists in cixiid identification. Furthermore, the variation in Reptalus COI gene should be considered for future DNA barcode analyses on cixiid species. The correspondence between morphological and COI-based identifications suggests that this short DNA fragment can be a good identifier for this insect family. The presence of cixiids in barcoding databases has been restricted to very few species, and the uploading of Reptalus COI sequences may enrich this universal and easily accessible identification system.

Both COI and ITS2 sequences can be efficiently applied to the species identification of juveniles and females, for which a morphological identification tool is unavailable. From this perspective, this work represents a useful contribution to faunal studies and insect vector monitoring. First, the ability to correctly identify nymphs allows the collection period to be extended to the whole year, making possible a longer monitoring activity from the current couple of months when adults are present. Second, while adults tend to rapidly disperse and can have a more polyphagous feeding habit, nymphs are harboured exclusively on the root system, making feasible the unambiguous association with their actual host plants. So far, breeding plants of $R$. cuspidatus, $R$. melanochaetus, $R$. panzeri and $R$. quinquecostatus are unknown and, during our surveys, we were able to definitely associate $R$. cuspidatus with Artemisia verlotiorum Lamotte since many larvae were found on its roots.

The correct identification of the Reptalus host plants, together with the identification of plants that can act as a reservoir of plant pathogens for crop species, is of fundamental importance in designing a rational control strategy. The same total DNA preparations from Reptalus spp. can serve as a PCR template for insect species and stolbur phytoplasma identification (data not shown).

In conclusion, this study provides fast and reliable assays for the correct identification of four Reptalus species. Morphological features are suggested for genus identification while species discrimination within the genus can be easily achieved with ITS2 and/or COI sequence analysis. The integration of morphological and molecular approaches provides useful help in monitoring activities and the rational control of potential vector species.

\section{Acknowledgements}

The authors would like to thank all the people who kindly helped in sample collection, particularly Mirko Bacchiavini and Pasquale Mazzio (Consorzio Fitosanitario Provinciale of Reggio Emilia), Ruggero Mazzilli, Paolo Fontana and Mauro Daccordi. The authors also thank Federica Tota for helping in laboratory analysis and Prof. Hannelore Hoch for her precious advices. This work was supported by the Piemonte Region and the MIUR-PRIN 2008.

\section{References}

Behere, G.T., Tay, W.T., Russell, D.A. \& Batterham, P. (2008) Molecular markers to discriminate among four pest species of Helicoverpa (Lepidoptera: Noctuidae). Bulletin of Entomological Research 98, 599-603.

Bosco, D., Palermo, S., Mason, G., Tedeschi, R., Marzachì, C. \& Boccardo, G. (2002) DNA-based methods for the detection and the identification of phytoplasmas in insect vector extracts. Molecular Biotechnology 22, 9-18.

Bressan, A., Sémétey, O., Nusillard, B., Clair, D. \& BoudonPadieu, E. (2008) Insect vectors (Hemiptera: Cixiidae) and pathogens associated with the disease syndrome 'basses richesses' of sugar beet in France. Plant disease 92, 113-119.

Březíková, M. \& Linhartová, S. (2007) First report of potato stolbur phytoplasma in Hemipterans in southern Moravia. Plant Protection Science 43, 73-76.

Ceotto, P.C. \& Bourgoin, T. (2008) Insights into the phylogenetic relationships within Cixiidae (Hemiptera: Fulgoromorpha): cladistic analysis of a morphological data set. Systematic Entomology 33, 484-500.

Ceotto, P.C., Kergoat, G.J., Rasplus, J.Y. \& Bourgoin, T. (2008) Molecular phylogenetics of cixiid planthoppers (Hemiptera: Fulgoromorpha): New insights from combined analyses of mitochondrial and nuclear genes. Molecular Phylogenetics and Evolution 48, 667-678. 
Collins, F.H. \& Paskewitz S.M. (1996) A review of the use of ribosomal DNA (rDNA) to differentiate among cryptic Anopheles species. Insect Molecular Biology 5, 1-9.

Danet, J.L., Foissac, X., Zreik, L., Salar, P., Verdin, E., Nourrisseau, J.G. \& Garnier, M. (2003) 'Candidatus phlomobacter fragariae' is the prevalent agent of marginal chlorosis of strawberry in French production fields and is transmitted by the planthopper Cixius wagneri (China). Phytopathology 93, 644-649.

Duduk, B. \& Bertaccini, A. (2006) Corn with symptoms of reddening: new host of stolbur phytoplasma. Plant Disease 90, 1313-1319.

Hebert, P.D.N. \& Gregory, T.R. (2005) The promise of DNA barcoding for taxonomy. Systematic Biology 54, 852-859.

Hebert, P.D.N., Cywinska, A., Ball, S.L. \& deWaard, J.R. (2003) Biological identification through DNA barcodes. Proceedings of the Royal Society of London, Series B 270, 313-321.

Hebert, P.D.N., Penton, E.H., Burns, J.M., Janzen, D.H. \& Hallwachs, W. (2004) Ten species in one: DNA barcoding reveals cryptic species in neotropical skipper butterfly Astraptes fulgerator. Proceedings of the National Academy of Science 101, 14812-14817.

Hoch, H. (2004) Fauna Europaea: Cixiidae, Reptalus. Fauna Europaea version 1.1, available online at http://www. faunaeur.org.

Hogg, I.D. \& Hebert, P.D.N. (2004) Biological identification of springtails (Hexapoda: Collembola) from the Canadian Arctic, using mitochondrial DNA barcodes. Canadian Journal of Zoology 82, 749-754.

Holzinger, W.E., Kammerlander, I. \& Nickel, H. (2003) The Auchenorrhyncha of Central Europe - Die Ziekaden Mitteleuropas Volume 1: Fulgoromoropha, Cicadomorpha excl. Cicadellidae. 673 pp. Leiden, The Netherlands, Brill.

Jović, J., Cvrković, T., Mitrović, M., Krnjajić, S., Redinbaugh, M.G., Pratt, R.C., Gingery, R.E., Hogenhout, S.A. \& Toševski, I. (2007) Roles of stolbur phytoplasma and Reptalus panzeri (Cixiinae, Auchenorrhyncha) in the epidemiology of Maize redness in Serbia. European Journal of Plant Pathology 118, 85-89.

Julia, J.F., Dollet, M., Randles, J. \& Calvez, C. (1985) Foliar decay of coconut by Myndus taffini (FDMT): new results. Oléagineux 40, 19-27.

Koekemoer, L.L., Misiani, E.A., Hunt, R.H., Kent R.J., Norris, D.E. \& Coetzee, M. (2009) Cryptic species within Anopheles longipalpis from southern Africa and phylogenetic comparison with members of the An. funestus group. Bulletin of Entomological Research 99, 41-49.

Li, Z.-X. (2007) Molecular differentiation of the four most commonly occurring Trichogramma (Hymenoptera: Trichogrammatidae) species in China. European Journal of Entomology 104, 363-367.

Maixner, M. (2006) Grapevine yellows - Current developments and unsolved questions. In Proceedings of the $15^{\text {th }}$ meeting of the International Council for the Study of Virus and Virus-like Diseases of the Grapevine (ICVG), Stellenbosch, South Africa, 3-7 April 2006. Available online at http://www.icvg.ch/ data/maixner.pdf.

Mazzoni, V. (2005) Contribution to the knowledge of the Auchenorrhyncha (Hemiptera Fulgoromorpha and Cicadomorpha) of Tuscany (Italy). Redia 88, 85-102.

O'Brien, L.B. \& Wilson, S.W. (1985) Planthopper systematics and external morphology. pp. 61-102 in Nault, L.R. \&
Rodriguez, J.G. (Eds) The Leafhoppers and Planthoppers. New York, NY, USA, John Wiley and Sons.

Ossiannilsson, F. (1978) The Auchenorrhyncha (Homoptera) of Fennoscandia and Denmark. Part 1: introduction, infraorder Fulgoromorpha. 222 pp. Klampenborg, Denmark, Scandinavian Science Press Ltd.

Palermo, S., Elekes, M., Botti, S., Ember, I., Alma, A., Orosz, A., Bertaccini, A. \& Kölber, M. (2004) Presence of stolbur phytoplasma in Cixiidae in Hungarian vineyards. Vitis $\mathbf{4 3}$, 201-203.

Pinzauti, F., Trivellone, V. \& Bagnoli, B. (2008) Ability of Reptalus quinquecostatus (Hemiptera: Cixiidae) to inoculate stolbur phytoplasma to artificial feeding medium. Annals of Applied Biology 153, 299-305.

Riedle-Bauer, M., Tiefenbrunner, W., Otreba, J., Hanak, K., Schildberger, B. \& Regner, F. (2006) Epidemiological observations on bois noir in Austrian vineyards. Mitteilungen Klosterneuburg, Rebe und Wein, Obstbau und Früchteverwertung 56, 166-170.

Roe, A.D. \& Sperling, F.A.H. (2007) Population structure and species boundary delimitation of cryptic Dioryctria moths: an integrative approach. Molecular Ecology 16, 3617-3633.

Sforza, R. \& Bourgoin, T. (1998) Female genitalia and copulation of the planthopper Hyalesthes obsoletus Signoret (Hemiptera, Fulgoromorpha, Cixiidae). Annales de la Société Entomologique de France (N.S.) 34, 63-70.

Sforza, R., Clair, D., Daire, X., Larrue, J. \& Boudon-Padieu, E. (1998) The role of Hyalesthes obsoletus (Hemiptera: Cixiidae) in the occurrence of bois noir of grapevines in France. Journal of Phytopathology 146, 549-556.

Simon, C., Frati, F., Beckenbach, A., Crespi, B., Liu, H. \& Flook, P. (1994) Evolution, weighting and phylogenetic utility of mitochondrial gene sequences and a compilation of conserved polymerase chain reaction primers. Annals of Entomological Society of America 87, 651-701.

Sinclair, C.S. \& Gresens, S.E. (2008) Discrimination of Cricotopus species (Diptera: Chironomidae) by DNA barcoding. Bulletin of Entomological Research 98, 555-563.

Smith, M.A., Fisher, B.L. \& Hebert, P.D.N. (2005) DNA barcoding for effective diversity assessment of a hyperdiverse arthropod group: the ants of Madagascar. Philosophical Transactions of the Royal Society of London, Series B 360, 1825-1834.

Trivellone, V., Pinzauti, F. \& Bagnoli, B. (2005) Reptalus quinquecostatus (Dufour) (Auchenorrhyncha Cixiidae) as a possible vector of Stolbur-phytoplasma in a vineyard in Tuscany. Redia 88, 103-108.

Weintraub, P.J. \& Beanland, L. (2006) Insect vectors of phytoplasmas. Annual Review of Entomology 51, 91-111.

Wilson, S.W. (2005) Keys to the families of Fulgoromorpha with emphasis on planthoppers of potential economic importance in the south-eastern United States (Hemiptera: Auchenorrhyncha). Florida Entomologist 88, 464-481.

Wilson, S.W. \& Tsai, J.H. (1982) Descriptions of the immature stages of Myndus crudus (Homoptera: Fulgoroidea: Cixiidae). Journal of the New York Entomological Society 90, 166-175.

Wilson, S.W., Mitter, C., Denno, R.F. \& Wilson, M.R. (1994) Evolutionary patterns of host plant use by delphacid planthoppers and their relatives. pp. 7-45 in Denno, R.F. \& Perfect, T.J. (Eds) Planthoppers: Their Ecology and Management. New York, NY, USA, Chapman and Hall. 